\title{
Hepatoprotective role of liver fatty acid binding protein in acetaminophen induced toxicity
}

\author{
Yu Gong ${ }^{1}$, Guqi Wang ${ }^{3}$, Yuewen Gong ${ }^{1}$, Jing Yan ${ }^{1}$, Yufei Chen ${ }^{1}$ and Frank J Burczynski, ${ }^{1 *}$
}

\begin{abstract}
Background: FABP1 has been reported to possess strong antioxidant properties. Upon successful transfection of the Chang cell line, which has undetectable FABP1 mRNA levels, with human FABP1 cDNA, the Chang cells were shown to express FABP1. Using the transfected and control (normal) Chang cells and subjecting them to oxidative stress, transfected cells were reported to be associated with enhanced cell viability. This study extends those observations by investigating the effect of FABP1 on acetaminophen (AAP)-induced hepatotoxicity. We hypothesized that presence of FABP1 would enhance cell viability compared to control cells (vector transfected cells).
\end{abstract}

Methods: Following AAP treatment of Chang FABP1 transfected and control cells, cell viability, oxidative stress, and apoptosis were evaluated using lactate dehydrogenase $(\mathrm{LDH})$ release, the fluorescent probe DCF, and Bax expression, respectively.

Results: FABP1 cDNA transfected cells showed greater resistance against AAP toxicity than vector transfected cells. Significantly lower LDH levels ( $p<0.05)$ were observed as were lower DCF fluorescence intensity $(p<0.05)$ in FABP1 cDNA transfected cells compared to vector transfected cells. FABP1 expression also attenuated the expression of Bax following AAP induced toxicity.

Conclusion: FABP1 attenuated AAP-induced toxicity and may be considered a cytoprotective agent in this in vitro model of drug induced oxidative stress.

Keywords: FABP1, Acetaminophen, Oxidative stress, Liver, Apoptosis

\section{Background}

Fatty acid binding protein (FABP) was first discovered in 1969 by Levi et al. [1]. Liver fatty acid binding protein (FABP1), named after the tissue in which it was first identified, is approximately a $14-15 \mathrm{kDa}$ protein mainly present in the cytoplasm of hepatocytes but expressed in many other tissues [2,3]. FABP1's main function is thought to be the intracellular transport of lipophilic substrates such as long chain fatty acids. FABP1 also interacts indirectly with the peroxisome proliferator-activated receptor alpha (PPAR $\alpha)$, which is a key regulator of lipid homeostasis in hepatocytes and a target for fatty acids and hypolipidemic drugs, by transporting PPAR $\alpha$ agonists

\footnotetext{
* Correspondence: burczyn@cc.umanitoba.ca

${ }^{1}$ Faculty of Pharmacy, University of Manitoba, 750 McDermot Avenue,

Winnipeg, MB R3E 0T5, Canada

${ }^{2}$ Department of Pharmacology and Therapeutics, Faculty of Medicine,

University of Manitoba, Winnipeg, MB, Canada

Full list of author information is available at the end of the article
}

to its site. Thus, FABP1 acts as a cytosolic gateway by directing PPAR ligands to the nucleus [4].

A new antioxidant property of FABP1 has recently been uncovered $[5,6]$. In its primary structure FABP1 contains seven methionine and one-cysteine amino acids. These groups are regarded as cellular scavengers of activated xenobiotics and are involved in trapping of free radicals [7]. Thus, in this study we used an acetaminophen induced toxicity model in cultured cells to assess the antioxidant function of FABP1.

Acetaminophen (AAP), 4-hydroxyacetanilide, is a widely utilized drug known for its analgesic and antipyretic properties. When used at therapeutic levels it is safe, however, an acute or cumulative overdose can cause severe liver injury with the potential of liver failure [8]. At therapeutic doses, AAP is primarily detoxified by glucuronidation and sulfation with a small fraction metabolized by cytochrome P-450-dependent mixed function oxidase 
system to a highly reactive $\mathrm{N}$-acetyl-p-benzo-quinonemine (NAPQ1) metabolite [9]. The metabolite reacts with glutathione (GSH) spontaneously or is catalyzed by glutathione-S-transferases to form a GSH-adduct which is mainly excreted into bile through Mrp2 without significant toxicity [10]. After an AAP overdose, however, glucuronidation and sulfation are insufficient to detoxify AAP. A large fraction of the drug becomes available for metabolism by cytochrome P450, leading to a rapid depletion of hepatic GSH levels. Once GSH is exhausted, any remaining NAPQI formed will react with alternative targets, in particular cellular proteins [11]. In addition to NAPQI, other cellular effects of AAP toxicity further exacerbates cellular oxidative stress which in turn contributes to the cell injury process [12].

The present study investigates the hepatoprotective effect of FABP1 in acetaminophen-induced toxicity using the Chang cell line. Chang cells were originally thought to be derived from normal liver tissue, but subsequently found to have been established via HeLa cell contamination. The rationale for using this cell line, however, rests in the fact that these cells were shown to be devoid FABP1 [5], yet have the metabolic enzymes responsible for metabolizing AAP to the NAPQ1 reactive species [12]. Thus, it is an ideal cell line to study the biological and bioprotective effects of FABP1.

\section{Methods \\ Materials}

Dulbecco's modified Eagle's medium (DMEM), sodium pyruvate, penicillin, streptomycin, Geneticin (G-418) and sodium pyruvate were purchased from GIBCO/BRL (Life Technology, Burlington, ON). Acetaminophen, calf serum and $\beta$ - nicotinamide adenine di-nucleotide, reduced form of $\beta-\mathrm{NADH}$, were purchased from Sigma (Sigma, Co., St. Louis, MO). The cellular toxicity assay kit (WST-1) was purchased from Roche (Roche Diagonstics GmbH, Mannheim, Germany), anti-Bax (N-20) monoclonal antibody was from Santa Cruz Biotechnology, Inc., horseradish peroxidase conjugated anti-mouse lgG (sheep) was from Amersham biosciences, anti-rabbit lgG horseradish peroxidise linked whole antibody was from GE healthcare, and rainbow molecular weight marker was purchased from Invitrogen. FABP1 polyclonal antibody was generated in our laboratory.

\section{Methods}

\section{Cell cultures}

Chang cells were obtained from American Type Culture Collection (Manassas, VA, USA). Vector and FABP1 cDNA transfected Chang cells [5] were grown in DMEM supplemented with $100 \mathrm{U}$ of penicillin $/ \mathrm{ml}$, $100 \mu \mathrm{g}$ streptomycin $/ \mathrm{ml}$ and $10 \%$ calf serum, in a humidified $37^{\circ} \mathrm{C}$ incubator with an atmosphere of 95\% air and 5\% $\mathrm{CO}_{2}$. The transfected Chang cells were maintained in the presence of G418 (Geneticin) at a concentration of $200 \mathrm{mg} / \mathrm{L}$.

Cells were seeded at a density of $1 \times 10^{4}$ cells/well (for WST-1 and DCF assay, 96-well plates), $1 \times 10^{5}$ cells/well (for LDH assay, 6-well plates) and $1 \times 10^{6}$ cells/well (for Western blot, $60 \mathrm{~mm}$ dishes) in DMEM medium and incubated overnight for adherence. The next day cell cultures were washed once with warm phosphate-buffered saline (PBS) and incubated with AAP for 3, 6, 12, and $24 \mathrm{hrs}$ at $37^{\circ} \mathrm{C}$ in a humidified incubator in an atmosphere of $95 \%$ air and $5 \% \mathrm{CO}_{2}$. At the end of the incubation period, cells were prepared for the various assays described below.

\section{Cell viability}

The cell proliferation reagent WST-1 is based on the metabolic activity of viable cells. WST-1 $(10 \mu \mathrm{l} /$ well $)$ was added to cells that had already been treated with AAP (0 mM, $0.5 \mathrm{mM}, 1 \mathrm{mM}, 5 \mathrm{mM}, 10 \mathrm{mM}$, and $20 \mathrm{mM}$ ) for $3,6,12$, and 24 hrs, followed by $3 \mathrm{hrs}$ incubation with WST-1. Cell viability was measured using a spectra Max 190 (Molecular Devices) plate reader at $440 \mathrm{~nm}$.

The release of lactate dehydrogenase (LDH) from cells during the incubation period with AAP was used to determine cell damage. Briefly, after treatment with $10 \mathrm{mM}$ AAP for 3, 6, 12 and 24 hrs, LDH activity in the supernatant was determined as follows: a $10 \%(\mathrm{v} / \mathrm{v}) 2.5 \mathrm{mM}$ NADH was mixed with $10 \%(\mathrm{v} / \mathrm{v}) 25 \mathrm{mM}$ pyruvate in a Tris-KCl buffer $(50: 150 \mathrm{mM}, \mathrm{PH}=7.4)$ on the day of the assay and equilibrated to $25^{\circ} \mathrm{C}$ in a water bath prior to use. Aliquots $(50 \mu \mathrm{l})$ of the culture supernatants (containing $\mathrm{LDH}$ ) were added to a quartz cuvette that contained $1000 \mu \mathrm{l}$ substrate solution and then measured in UVvisible recording spectrometer (UV-160). Change in absorbance at $340 \mathrm{~nm}$ was directly proportional to LDH activity in the supernatant samples.

\section{DCF measurements}

Fluorescence intensity of DCF from reactive oxygen species (ROS) formed in cell cultures was assessed using a Wallac 1420 multilable counter (Perkin Elmer). A $10 \mathrm{mM}(4.87 \mathrm{mg} / \mathrm{ml})$ stock solution of 2,7- dichlorofluorescein diacetate $\left(\mathrm{H}_{2} \mathrm{DCFDA}\right)$ was prepared daily in ethanol and stored at $-20^{\circ} \mathrm{C}$ until required and diluted to $1 \mathrm{mM}$ with PBS prior to each study. Following incubation with AAP, cells were washed twice with $\mathrm{Ca}^{++} / \mathrm{Mg}^{++}-\mathrm{PBS}$ and incubated with $100 \mu \mathrm{M}$ 2,7-dichlorofluorescin diacetate $\left(\mathrm{DCFH}_{2}-\mathrm{DA}\right)$ at room temperature in the dark for $30 \mathrm{~min}$. Mean of fluorescence intensity was calculated from 4-wells of control and drug-treated cells from six separate experiments. 


\section{Western blot}

After AAP treatment, protein extracts were prepared from cell cultures using RIPA Buffer $(50 \mathrm{mM}$ Tris- $\mathrm{HCl}$ pH 7.4, $150 \mathrm{mM} \mathrm{NaCl}, 1 \mathrm{mM}$ PMSF, $1 \mathrm{mM}$ EDTA, $5 \mu \mathrm{g} / \mathrm{ml}$ Aprotinin, $5 \mu \mathrm{g} / \mathrm{mL}$ Leupeptin, 1\% Triton $\mathrm{x}-$ $100,1 \%$ Sodium deoxycholate, $0.1 \%$ SDS). Briefly, cell pellets $\left(1 \times 10^{6}\right)$ were washed once with ice-cold PBS and incubated with $1 \mathrm{ml}$ RIPA buffer on ice for $20 \mathrm{~min}$, vortexing 2-3 times. The lysate was centrifuged for $5 \mathrm{~min}$ at $4^{\circ} \mathrm{C}$ at $20,000 \mathrm{~g}$ in microfuge tubes. Supernatants were transferred to clean tubes. Protein concentration was measured using the BCA Protein Assay. Samples were stored at $-80^{\circ} \mathrm{C}$ until required. The optical density values of each target protein band were determined using NIH Imaging software.

\section{Statistical analyses}

Statistical analyses of the treatment groups were carried out by $t$ test (unpaired) where 2 groups were compared while a two-way ANOVA was used for multiple comparisons. Statistical differences with $P$ values $<0.05$ were taken as significant.

\section{Results}

\section{Cellular viability}

Cytotoxicity induced by AAP in vector and FABP1 cDNA transfected cells using the cell proliferation reagent WST1 is shown in Figure 1. AAP induced a dose-dependent cytotoxicity in both vector and FABP1 cDNA transfected cells. The FABP1 cDNA transfected cells, however, showed lower cytotoxicity then vector-transfected cells following $3 \mathrm{hrs}$ of AAP treatment. Drug exposure times of $6 \mathrm{hrs}$, $12 \mathrm{hrs}$ and $24 \mathrm{hrs}$, were also investigated with results similar to those shown for 3 hrs (data not shown). Vector

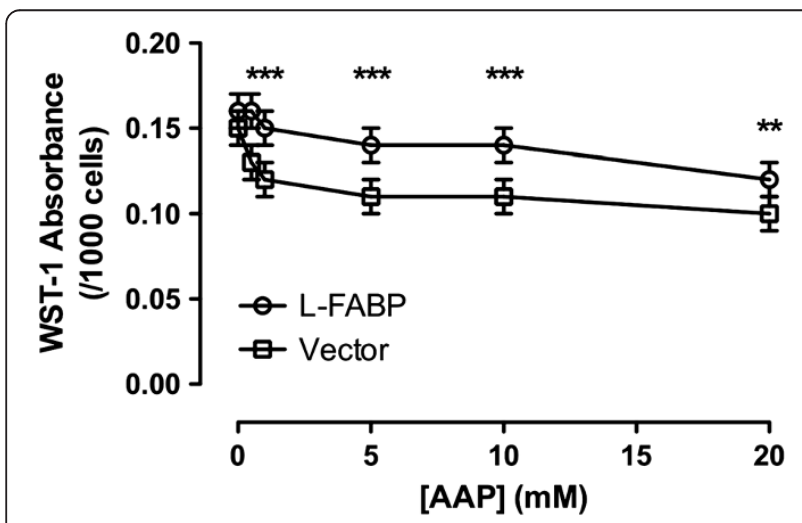

Figure 1 Cytotoxicity of vector and FABP1 transfected cells exposed to various AAP concentrations for $3 \mathrm{hrs}$ as measured by WST-1. The two groups of cells were treated with $0,0.5,1,5,10$, $20 \mathrm{mM}$ concentrations of AAP for 3 hrs. Data show mean $\pm \mathrm{SE} ; \mathrm{n}=6$; ${ }^{* *} \mathrm{p}<0.01$ (for $20 \mathrm{mM} \mathrm{AAP}$ ), ${ }^{* *} \mathrm{p}<0.001$ (for $0.5 \mathrm{mM}, 1.0 \mathrm{mM}, 5 \mathrm{mM}$, and $10 \mathrm{mM}$ AAP) between FABP1 cDNA and vector transfected cells during the same time period. transfected Chang cells showed a 15\%, 19\%, 23\%, 27\%, and $37 \%$ decrease in viability at concentrations of $0.5 \mathrm{mM}, 1 \mathrm{mM}, 5 \mathrm{mM}, 10 \mathrm{mM}$, and $20 \mathrm{mM}$ AAP, respectively; while cell viability in the FABP1 cDNA transfected cells showed a $2 \%, 6 \%, 14 \%, 17 \%$, and $23 \%$ reduction at the same concentrations, suggesting that FABP1 might have a cytoprotective role against AAP induced cytotoxicity. Comparing the FABP1 cDNA transfected cells to the vector transfected cells at AAP concentrations of $0.5 \mathrm{mM}, 1.0 \mathrm{mM}, 5 \mathrm{mM}$, and $10 \mathrm{mM}$ showed highly significant differences at the $\mathrm{p}<0.001$ level, while an AAP concentration of $20 \mathrm{mM}$ was significant at the $\mathrm{p}<0.01$ level. There was no statistical difference between the two cell types in the absence of AAP.

\section{ROS levels}

Oxidative stress is one of major causes of AAP induced cell injury. As a measure of reactive oxygen species (ROS) we used the ROS-sensitive probe 2,7-dichlorofluorescein diacetate $\left(\mathrm{H}_{2} \mathrm{DCFDA}\right)$ to monitor AAP induced cellular oxidative stress. Figure 2 shows DCF fluorescence results from experiments where vector and FABP1 cDNA transfected cells were incubated for $3 \mathrm{hrs}$ with $1 \mathrm{mM}, 5 \mathrm{mM}$, and $10 \mathrm{mM}$ AAP. Cells incubated with AAP for 6 hrs showed similar results (data not shown). AAP induced a dose-dependent oxidative stress in both vector-transfected cells and FABP1 cDNA transfected cells. DCF fluorescence intensity in FABP1 cDNA transfected cells was, however, significantly reduced $(p<0.05)$ compared to vector transfected cells at each AAP concentration (Figure 2). Compared to vector transfected cells, DCF fluorescence intensity of FABP1 cDNA transfected cells decreased by $35 \% \pm 5 \%$ at $1 \mathrm{mM}$

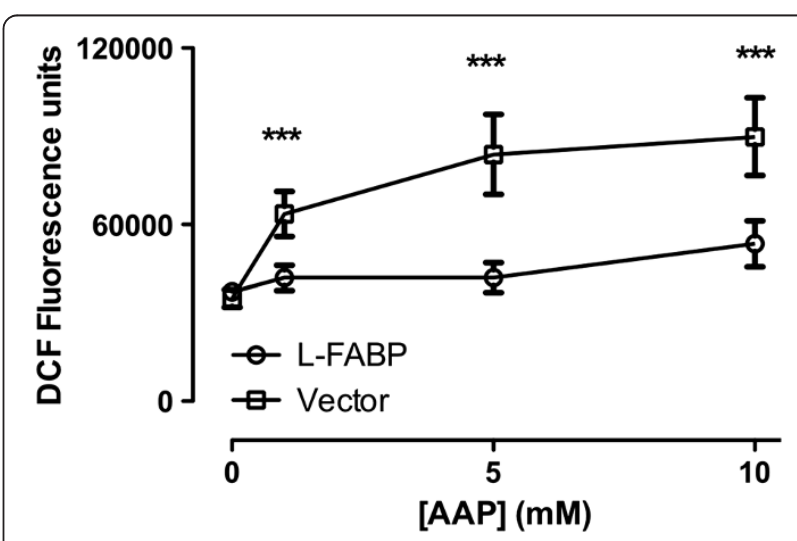

Figure 2 DCF fluorescence intensity of vector and FABP1 CDNA transfected cells in the presence of $1 \mathrm{mM}, 5 \mathrm{mM}, 10 \mathrm{mM}$ AAP for $\mathbf{3}$ hours. Cells were cultured in black 96 -well plates. After AAP treatment H2DCFDA (1 mM) was loaded into wells for 30 minutes. Cellular fluorescence in each well was measured and immediately recorded. Date represent mean $\pm \mathrm{SEM} ; n=6 ;{ }^{* *} \mathrm{p}<0.001$ between FABP1 CDNA transfected and vector transfected cells during the same time period. 
AAP treatment; $39 \% \pm 5 \%$ at $5 \mathrm{mM}$ AAP treatment; and $46 \% \pm 5 \%$ at $10 \mathrm{mM}$ AAP treatment $(\mathrm{p}<0.001)$.

\section{LDH levels}

The protective effect of FABP1 in AAP induced liver failure was assessed by detecting cellular LDH release. Release of LDH into culture supernatant correlates with reduced cell membrane integrity and cell viability. As shown in Figure 3, a statistical decrease $(\mathrm{p}<0.01)$ in supernatant LDH activity was found in FABP1 cDNA transfected cells only after 12 and 24 hrs of 10 mM AAP treatment compared with vector transfected cells. No statistical difference was observed in the 3 hrs AAP treatment group compared to the control group, suggesting that LDH release may be a late event in AAP induced cell injury that is preventable by FABP1.

\section{Bax and FABP1 levels}

Western blot analysis was used to detect the expression of the pro-apoptotic protein Bax in cells following $0 \mathrm{hrs}, 3 \mathrm{hrs}, 6 \mathrm{hrs}, 12 \mathrm{hrs}$, and $24 \mathrm{hrs}$ incubation with $10 \mathrm{mM}$ AAP. FABP1 cDNA transfected cells had lower levels of Bax then vector transfected cells at each time period ( $\mathrm{p}<0.05$; see Figure 4$)$. Bax level in the vectortransfected cells started to increase following $3 \mathrm{hrs}$ incubation with AAP and peaked at 12 hrs. Bax level in the FABP1 cDNA transfected cells remained constant until $12 \mathrm{hrs}$ when the Bax level statistically increased from the 6 hrs level $(\mathrm{p}<0.05)$.

To verify the role of FABP1 in AAP induced toxicity, FABP1 expression was analysed in each group. As expected there was no FABP1 present in the vectortransfected group while the FABP1 cDNA transfected

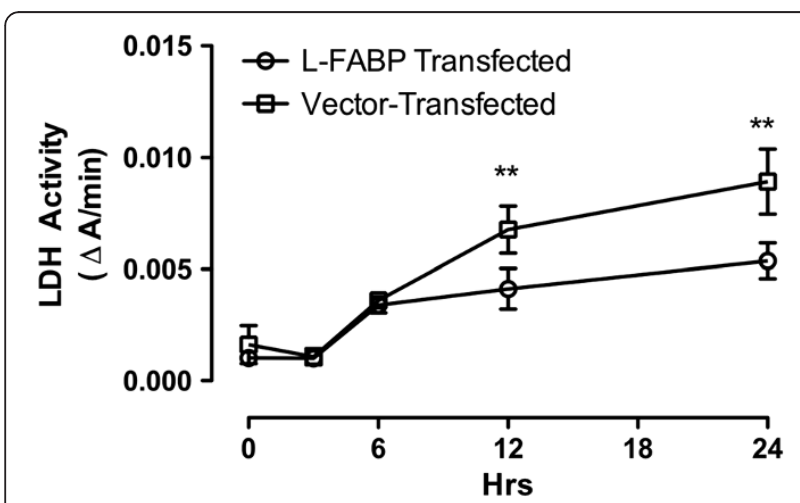

Figure $3 \mathrm{LDH}$ release from FABP1 CDNA and vector transfected cells subjected to $10 \mathrm{mM}$ AAP treatment for $3 \mathrm{hrs}, 6 \mathrm{hrs}, 12 \mathrm{hrs}$, and 24 hrs. Negative control experiments were performed by incubating cells with no serum DMEM for 24 hrs. LDH absorbance was measured at $340 \mathrm{~nm}$ and expressed as the rate of absorbance change per minute. Data represent mean \pm SEM $(n=4)$, ${ }^{* *} p<0.01$ LDH activity of FABP1 CDNA transfected cells compared with vector transfected cells during the same time period.

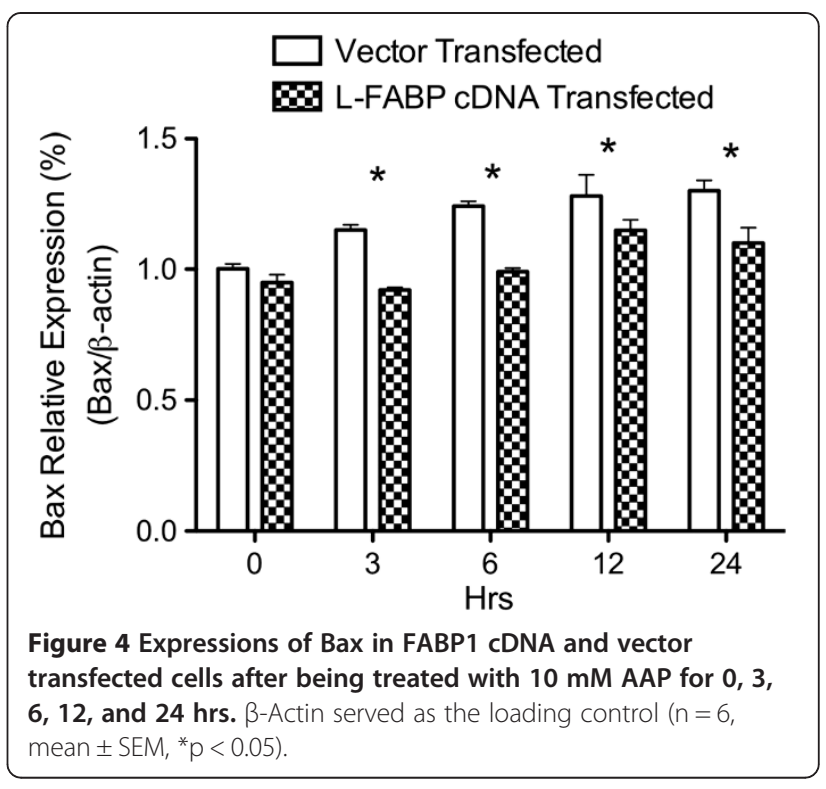

showed presence of the protein (Figure 5). The FABP1 level decreased over time in the AAP treated group. The slope of the regression line was significantly different from zero $(\mathrm{p}<0.05)$, suggesting that either the AAP toxicity damaged transcriptional/translational events or cells were made leaky such that the FABP1 was able to efflux from cells.

\section{Discussion}

Acetaminophen (AAP) is an effective over the counter medication for relief of minor pain and fever. A small fraction of the AAP dose is metabolized by CYP 2E1 to a highly reactive $\mathrm{N}$-acetyl-p-benzoquinone imine (NAPQI) metabolite. This metabolite is inactivated by glutathione or GSH within the liver. However, if the concentration of NAPQI is high, liver damage can occur. In severe cases liver failure and death occur. Despite its widespread use,

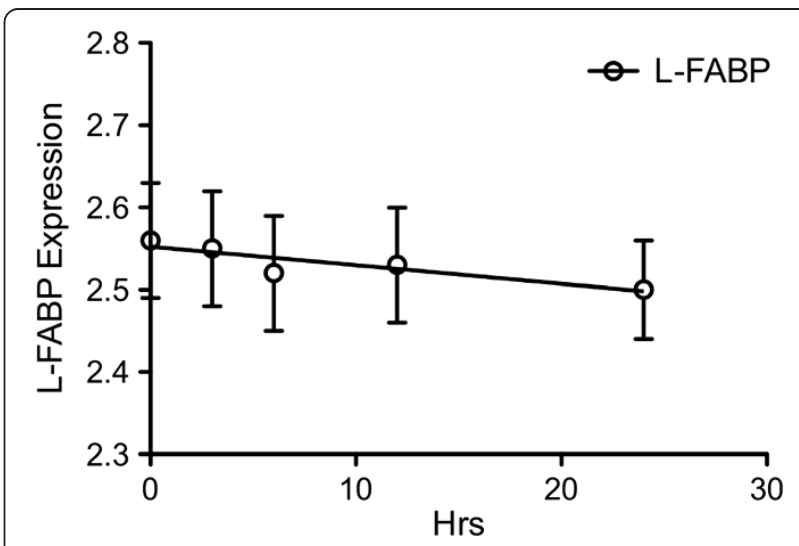

Figure 5 Expressions of FABP1 in FABP1 CDNA transfected cells after being treated with $10 \mathrm{mM}$ AAP for $0,3,6,12$, and $24 \mathrm{hrs}$ $(n=6$, mean \pm SEM). 
the mechanism of AAP's hepatocellular injury is still being investigated. Many studies have reported impaired mitochondrial respiration [13,14], depletion of hepatocellular ATP levels $[15,16]$, opening of the mitochondrial membrane permeability transition pore [17], and increased levels of glutathione disulfide (GSSG) or the ratio of GSSG:GSH, suggesting the involvement of an oxidant stress following AAP overdose $[15,18]$. In response to high levels of ROS the nascent hepatocyte antioxidants may not provide sufficient capacity to inactivate them, other antioxidant defence systems are expected to take effect. FABP1, with its high affinity and capacity to bind lipophilic oxidative products $[19,20]$, is a likely candidate for further protecting hepatocytes from ROS.

Our previous work showed that Chang cells were devoid of FABP1. Transfecting the Chang cell line with FABP1 cDNA gave us an opportunity to study this protein in different models of oxidative stress. Using a hypoxia/reoxygenation as well as a $\mathrm{H}_{2} \mathrm{O}_{2}$ induced oxidative stress models [5], we reported that while FABP1 cDNA transfected cells had the same complement of intracellular antioxidant enzymes as the vector transfected cell line, FABP1 cDNA transfected cells were associated with much less ROS levels, suggesting that FABP1 is somehow involved in inactivating free radicals. Yan et al. [21] investigated the mechanism for the antioxidant protective function of FABP1. Rat FABP1 is known to have seven methionine groups in positions $1,19,22,74,85$, 91, and 113, as well as one cysteine group in position 69 . Methionine and cysteine are known to react with ROS. Using a recombinant form of rat FABP1 that was cultured in E. coli, isolated and purified, the group showed that indeed the methionine groups of FABP1 were associated with reactive oxygen as assessed by MALDI-TOF. Moreover, FABP1 was shown to react with free radicals in both hydrophilic and lipophilic domains of the cell. Using AAPH as a hydrophilic free radical generator the group determined that methionine 1, 19, 22, 91, and 113 were oxidized. In the lipophilic environment, using AMVN as the lipophilic free radical generator, methionine $1,19,22$, and 113 were only reactive. Methionine 74 and 85 were unreactive in both systems suggesting that these groups may be buried deep within the binding site of FABP1 while the other reactive groups are surface exposed. Interestingly, methionine 91 did not react with any free radicals in the lipophilic domain. This suggested that FABP1 might orientate itself to the membrane allowing other methionine groups access to react with free radicals at the membrane surface. FABP interaction with membrane surfaces has been suggested to occur with FABP2 (intestinal fatty acid binding protein) but not with FABP1 [22].

In this study we investigated the role of FABP1 in drug-induced liver damage. The data show a rapid onset of an intracellular oxidative stress as early as $3 \mathrm{hrs}$ in cultured cells using 2,7-dichlorofluorescein diacetate $\left(\mathrm{H}_{2} \mathrm{DCFDA}\right)$ as a marker of intracellular free radical levels. There was a dose-dependent increase in released ROS induced by AAP with DCF fluorescence intensities being significantly lower in FABP1 cDNA transfected cells compared to the vector transfected cells (Figure 2). AAP induced oxidative stress was studied by other groups such as Bajt et al. [23] who showed that a greater than 10 fold increase in ROS levels between 3.5 and $12.5 \mathrm{hrs}$ resulted following $5 \mathrm{mM}$ AAP treatment in cultured murine hepatocytes. Pretreatment of hepatocytes with $20 \mathrm{mM} \mathrm{N}$-acetylcysteine was shown to enhance cellular glutathione content and suppressed the AAPinduced decrease in cell viability. Bajt concluded that AAP-induced oxidant stress precedes cell necrosis and the oxidant stress is involved in the propagation of cell injury.

The effect of FABP1 on AAP-induced cell damage was assessed using the WST-1 assay in our study, which depends on mitochondrial respiration [24,25]. Results from this assay indicated a substantial functional deterioration of hepatocytes following AAP treatment. Similar to the DCF assay, results showed that the cytotoxicity induced by AAP was dose-dependent and statistical differences were observed between FABP1 cDNA and vector transfected cells following $3 \mathrm{hrs}$ drug treatment (Figure 1). Thus, FABP1 protects cellular mitochondrial function in some way. One possibility is by inactivating cytosolic free radicals. These reactive species are not able to interact with the mitochondrial membrane, thus, preserving cellular function. AAP also caused a progressive release of LDH into the culture media, showing cellular damage. The presence of FABP1 attenuated this increase but only at the latter stages of AAP induced cell injury since LDH release only became statistically significant after $12 \mathrm{hrs}$ of treatment. As well as being present in the cytosol, FABP1 is also present in the mitochondria. It is likely that FABP1 plays an early protective role in AAP induced mitochondrial impairment through scavenging free radicals within the mitochondria itself as well as in the cytosol.

The mechanism of AAP-induced cell death is not completely understood. Of the events leading to apoptotic and/or necrotic cell death, Bax seems to be central for the mitochondrial-dependent mechanisms. Bax is a pro-apoptotic $\mathrm{Bcl}-2$ family member that plays a pivotal role in the formation of the mitochondrial permeability pore. Higher levels of Bax are associated with changes in the outer membrane permeability, which are responsible for changes in the inner mitochondrial membrane that leads to disruption in cell function (e.g., membrane potential, cell swelling, leakage). Deletion of Bax has been shown to be associated with dramatic reduction in 
necrotic injury during myocardial infraction [26]. Thus, Bax may modulate necrosis through mechanisms that are distinct from apoptosis [26,27]. In our study, decreased Bax levels were seen in the AAP treated FABP1 cDNA transfected group at all time points (Figure 4). In the vector-transfected groups the Bax level started to statistically increase at $3 \mathrm{hrs}$ and peaked at $12 \mathrm{hrs}$. This was not seen in the FABP1 cDNA transfected cells. In the FABP1 cDNA transfected group the Bax level increased only after $12 \mathrm{hr}$ incubation with AAP. Thus, FABP1 shows a higher protective ability at the early time points ( 3 and 6 hrs) by preventing the increase in Bax level. At the late time points (12 and $24 \mathrm{hrs}$ ), Bax level in the FABP1 cDNA transfected group was lower than in the vector-transfected group but still higher than at the 6 hrs FABP1 cDNA transfected group. FABP1 levels, however, were also declining during the late time points. A rationale explanation for the declining FABP1 levels is not apparent. Studies aimed at assessing the time course of FABP1 mRNA activity would be necessary to explain the decrease in FABP1 levels. Presence of necrosis may be a possibility that leads to the release of FABP1. Nevertheless a strong correlation exists between FABP1 and Bax levels, showing that FABP1 prevents cell death through a reduction in Bax activity. Although our work cannot discern whether the higher (or lower) levels of Bax is associated with Bax translocation to the mitochondria, it is reasonable to speculate that the increased levels would lead to increased translocation. Bajt had earlier reported that following $300 \mathrm{mg} / \mathrm{Kg}$ intraperitoneal AAP injection to C57BL/6 mice, Bax translocation from the cytosol to mitochondria occurs as early as $1 \mathrm{hr}$ [28]. Thus, FABP1 likely protects cells against AAP hepatotoxicity during the early time periods of hepatocyte injury.

LDH release is indicative of cell death. Membranes become leaky through a variety of processes including that of oxidative damage. Since release of LDH in our study reached statistical significance only after $12 \mathrm{hrs}$ of AAP treatment, this showed that although earlier time points were associated increased Bax level, later time points involved necrosis. As stated above apoptosis and necrosis are not completely independent processes [29]. These two processes share a common mitochondrial permeability transition (MPT) pathway. When the MPT occurs abruptly, ATPase becomes activated which depletes ATP levels leading to membrane rupture and oncotic necrosis. However, the ATP level can remain constant (baseline condition) when the MPT proceeds relatively slowly or the ATPase is inhibited by glycolysis or oligomycin. Under these conditions, necrosis can be blocked and apoptosis occurs. At any time, ATP depletion can supervene to cause secondary necrosis. A new term, necrapoptosis has been introduced to describe a death process that begins with death signals or toxic stress, proceeds by shared pathways, but results in either cell lysis (oncotic necrosis) or programmed cellular resorption (apoptosis) depending on other factors, such as ATP [29]. In our study FABP1 attenuated the increased LDH release. It is not clear on the exact mechanism (direct or indirect) for the FABP1's hepatoprotective effect but we speculate that it may in part be likely due to its antioxidant role.

\section{Conclusions}

In summary, this study demonstrated that FABP1 plays an important protective function in AAP induced toxicity. The exact mechanism, however, is yet to be elucidated. Since oxidative stress is a major mitigating factor for cellular dysfunction in many diseases or drug induced complications, it seems logical that FABP1 levels could be increased to help combat the released ROS levels.

Competing interests

The authors declare that they have no competing interests.

\section{Authors' contributions}

YG participated in study design, carried out the cell culture work and drafted the manuscript. YC performed some of the fluorescence studies and helped in the drafting of the manuscript. JY helped in the design of the studies. GW, $Y G$, and FJB were instrumental in conceiving the study design, obtaining the necessary research funds to carry out the work. All authors read and approved the final manuscript.

\section{Acknowledgments}

This work was supported through a Canadian Institute of Health Research and Manitoba Health Research Council Operating Grants.

\section{Author details}

${ }^{1}$ Faculty of Pharmacy, University of Manitoba, 750 McDermot Avenue, Winnipeg, MB R3E 0T5, Canada. ${ }^{2}$ Department of Pharmacology and

Therapeutics, Faculty of Medicine, University of Manitoba, Winnipeg, MB, Canada. ${ }^{3}$ Liver-Biliary-Pancreatic Center, Carolinas Medical Center Charlotte, Charlotte, NC 28232-2861, USA.

Received: 30 April 2013 Accepted: 3 March 2014 Published: 10 March 2014

\section{References}

1. Levi AJ, Gatmaitan Z, Arias IM: Two hepatic cytoplasmic protein fractions, $Y$ and $Z$, and their possible role in the hepatic uptake of bilirubin, sulfobromophthalein, and other anions. J Clin Invest 1969, 48(11):2156-2167.

2. Bordewick U, Heese M, Borchers T, Robenek H, Spener F: Compartmentation of hepatic fatty-acid-binding protein in liver cells and its effect on microsomal phosphatidic acid biosynthesis. Biol Chem Hoppe-Seyler 1989, 370(3):229-238.

3. Fahimi HD, Voelkl A, Vincent SH, Muller-Eberhard U: Localization of the heme-binding protein in the cytoplasm and of a heme-binding proteinlike immunoreactive protein in the nucleus of rat liver parenchymal cells: immunocytochemical evidence of the subcellular distribution corroborated by radioimmunoassay and immunoblotting. Hepatology 1990, 11(5):859-865.

4. Wolfrum C, Borchers T, Sacchettini JC, Spener F: Binding of fatty acids and peroxisome proliferators to orthologous fatty acid binding proteins from human, murine, and bovine liver. Biochemistry 2000, 39:1469-1474. 
5. Wang G, Gong Y, Anderson J, Sun D, Minuk G, Roberts MS, Burczynski FJ: Antioxidative Function of L-FABP in L-FABP Stable Transfected Chang Liver Cells. Hepatology 2005, 42:871-879.

6. Wang G, Shen H, Rajaraman G, Roberts MS, Gong Y, Jiang P, Burczynski F: Expression and antioxidant function of liver fatty acid binding protein in normal and bile-duct ligated rats. Eur J Pharmacol 2007, 560:61-68.

7. Bassuk JA, Tsichlis PN, Sorof S: Liver fatty acid binding protein is the mitosis-associated polypeptide target of a carcinogen in rat hepatocytes. Proc Natl Acad Sci USA 1987, 84:7547-7551.

8. Lee WM: Acetaminophen and the U.S. Acute Liver Failure Study Group: lowering the risks of hepatic failure. Hepatology 2004, 40(1):6-9.

9. Nelson SD: Metabolic activation and drug toxicity. J Med Chem 1982 25(7):753-765

10. Chen C, Hennig GE, Manautou JE: Hepatobiliary excretion of acetaminophen glutathione conjugate and its derivatives in transportdeficient (TR-) hyperbilirubinemic rats. Drug Metab Dispos 2003, 31(6):798-804.

11. Jollow DJ, Mitchell JR, Potter WZ, Davis DC, Gillette JR, Brodie BB: Acetaminophen-induced hepatic necrosis. II. Role of covalent binding in vivo. J Pharmacol Exp Ther 1973, 187(1):195-202.

12. Shon $\mathrm{YH}, \mathrm{Nam} \mathrm{KS}$ : Protective effect of moutan cortex extract on acetaminophen-induced cytotoxicity in human Chang liver cells. Biol Pharm Bull 2002, 25(11):1427-1431.

13. Meyers LL, Beierschmitt WP, Khairallah EA, Cohen SD: Acetaminopheninduced inhibition of hepatic mitochondrial respiration in mice. Toxicol Appl Pharmacol 1988, 93(3):378-387.

14. Ramsay RR, Rashed MS, Nelson SD: In vitro effects of acetaminophen metabolites and analogs on the respiration of mouse liver mitochondria. Arch Biochem Biophys 1989, 273(2):449-457.

15. Jaeschke $\mathrm{H}$ : Glutathione disulfide formation and oxidant stress during acetaminophen-induced hepatotoxicity in mice in vivo: the protective effect of allopurinol. J Pharmacol Exp Ther 1990, 255(3):935-941.

16. Tirmenstein MA, Nelson SD: Acetaminophen-induced oxidation of protein thiols. Contribution of impaired thiol-metabolizing enzymes and the breakdown of adenine nucleotides. J Biol Chem 1990, 265(6):3059-3065.

17. Masubuchi Y, Suda C, Horie T: Involvement of mitochondrial permeability transition in acetaminophen-induced liver injury in mice. $J$ Hepatol 2005, 42(1):110-116

18. Knight TR, Kurtz A, Bajt ML, Hinson JA, Jaeschke H: Vascular and hepatocellular peroxynitrite formation during acetaminophen toxicity: role of mitochondrial oxidant stress. Toxicol Sci 2001, 62(2):212-220.

19. Ek-Von Mentzer BA, Zhang F, Hamilton JA: Binding of 13-HODE and 15HETE to phospholipid bilayers, albumin, and intracellular fatty acid binding proteins. J Biol Chem 2001, 276(19):15575-15580.

20. Raza $H$, Pongubala JR, Sorof $S$ : Specific high affinity binding of lipoxygenase metabolites of arachidonic acid by liver fatty acid binding protein. Biochem Biophys Res Commun 1989, 161(2):448-455.

21. Yan J, Gong Y, She YM, Wang G, Roberts MS, Burczynski FJ: Molecular mechanism of recombinant liver fatty acid binding protein's antioxidant activity. J Lipid Res 2009, 50(12):2445-2454.

22. Thumser AEA, Storch J: Liver and intestinal fatty acid-binding proteins obtain fatty acids from phospholipid membranes by different mechanisms. J Lipid Res 2000, 41(4):647-656.

23. Bajt ML, Knight TR, Lemasters JJ, Jaeschke H: Acetaminophen-induced oxidant stress and cell injury in cultured mouse hepatocytes: protection by $\mathrm{N}$-acetyl cysteine. Toxicol Sci 2004, 80(2):343-349.

24. Bernas T, Dobrucki J: Mitochondrial and nonmitochondrial reduction of MTT: interaction of MTT with TMRE, JC-1, and NAO mitochondrial fluorescent probes. Cytometry 2002, 47(4):236-242.

25. Huet $\mathrm{O}$, Petit JM, Ratinaud MH, Julien R: NADH-dependent dehydrogenase activity estimation by flow cytometric analysis of 3-(4,5-dimethylthiazolyl-2-yl)-2,5-diphenyltetrazolium bromide (MTT) reduction. Cytometry 1992, 13(5):532-539

26. Whelan RS, Konstantinidis $K$, Wei $A C$, Chen $Y$, Reyna DE, Jha S, Yang $Y$, Calvert JW, Lindsten T, Thompson CB, Crow MT, Gavathiotis E, Dorn GW, O'Rourke B, Kitsis RN: Bax regulates primary necrosis through mitochondrial dynamics. Proc Natl Acad Sci USA 2012, 109(17):6566-6571.

27. Karch J, Kwong JQ, Burr AR, Sargent MA, Elrod JW, Peixoto PM, MartinezCaballero S, Osinska H, Cheng EH, Robbins J, Kinnally KW, Molkentin JD: Bax and Bak function as the outer membrane component of the mitochondrial permeability pore in regulating necrotic cell death in mice. elife 2013, 2:e00772.

28. Bajt ML, Farhood A, Lemasters JJ, Jaeschke H: Mitochondrial bax translocation accelerates DNA fragmentation and cell necrosis in a murine model of acetaminophen hepatotoxicity. J Pharmacol Exp Ther 2008, 324(1):8-14

29. Lemasters JJ: V. Necrapoptosis and the mitochondrial permeability transition: shared pathways to necrosis and apoptosis. Am J Physiol 1999, 276(1 Pt 1):G1-G6.

doi:10.1186/1471-230X-14-44

Cite this article as: Gong et al:: Hepatoprotective role of liver fatty acid binding protein in acetaminophen induced toxicity. BMC

Gastroenterology 2014 14:44

\section{Submit your next manuscript to BioMed Central and take full advantage of:}

- Convenient online submission

- Thorough peer review

- No space constraints or color figure charges

- Immediate publication on acceptance

- Inclusion in PubMed, CAS, Scopus and Google Scholar

- Research which is freely available for redistribution 